Published in final edited form as:

Future Oncol. 2015 ; 11(5): 719-733. doi:10.2217/fon.14.272.

\title{
Efficacy and Safety of Ruxolitinib in the Treatment of Patients with Myelofibrosis
}

\author{
Cecilia Arana $\mathrm{Yi}^{1}$, Constantine S. Tam ${ }^{2}$, and Srdan Verstovsek ${ }^{\star}, 3$ \\ 1 University of New Mexico Cancer Center, 1201 Camino de Salud NE, Albuquerque, NM 87131, \\ USA; Tel.: +1 505-272-4946; Fax: +1 505-925-0100; caranayi@salud.unm.edu \\ 2Division of Hematology and Oncology, Peter MacCallum Cancer Centre, St Andrew's Place, East \\ Melbourne, Victoria 3002, AUSTRALIA; Tel.: + 6139656 1700, Fax: + 6139656 1408; \\ constantine.tam@petermac.org \\ ${ }^{3}$ Department of Leukemia, MD Anderson Cancer Center, 1515 Holcombe Blvd Suite 428, \\ Houston, TX 77030, USA
}

\begin{abstract}
The JAK 1 and JAK2 inhibitor ruxolitinib has approved indications in myelofibrosis, a $B C R$ -

$A B L 1$-negative myeloproliferative neoplasm associated with progressive bone marrow fibrosis and shortened survival. In Phase III clinical studies, ruxolitinib provided rapid and durable improvement of myelofibrosis-related splenomegaly and symptoms irrespective of mutation status, and was associated with a survival advantage compared with placebo or best available therapy. Because of dose-dependent cytopenias, blood count monitoring and dose titration are important to optimize therapy. Specific precautions apply to the treatment of patients with or at risk of serious infections. Discontinuation of ruxolitinib generally leads to symptom return within 1 week. Ruxolitinib also is approved for treatment of patients with polycythemia vera who have had an inadequate response to or are intolerant of hydroxyurea.
\end{abstract}

\section{Keywords}

Ruxolitinib; JAK inhibitor; myelofibrosis; myeloproliferative neoplasm; polycythemia vera; primary myelofibrosis; splenomegaly

\section{Introduction}

Myelofibrosis (MF) is a heterogeneous $B C R-A B L 1$-negative myeloproliferative neoplasm (MPN) that may arise as primary MF (PMF) or through myelofibrotic transformation of other MPNs, namely essential thrombocythemia (ET) or polycythemia vera (PV) [1 ${ }^{-}$] . MF is a rare chronic disease that primarily affects older individuals [6,7]. The disease is associated with progressive bone marrow fibrosis, ineffective and extramedullary

\footnotetext{
*Author for correspondence: Tel.: +1 713-792-7305; Fax: +1 713-745-0930 sverstov@mdanderson.org.

Financial \& competing interests disclosure The authors have no other relevant affiliations or financial involvement with any organization or entity with a financial interest in or financial conflict with the subject matter or materials discussed in the manuscript apart from those disclosed.
} 
hematopoiesis, systemic inflammation and shortened survival; with splenomegaly, debilitating symptom burden and anemia being the most common clinical manifestations $[4,6,7]$. Some of the most prevalent constitutional or spleen-related symptoms in patients with MF include fatigue, night sweats, fever, pruritus, early satiety, unintentional weight loss, abdominal pain or discomfort, and bone pain [8-10]. To determine the prognosis of patients with MF at the time of diagnosis, the International Prognostic Scoring Systems (IPSS) has been developed [11]. Based on the number of risk factors present, patients are categorized as low (no risk factors), intermediate-1 (1 risk factor), intermediate-2 (2 risk factors) or high risk ( $\geq 3$ risk factors), with median survival times for each risk group ranging from 11 years (low risk) to 2 years (high risk). Risk factors for shortened survival included age more than 65 years, anemia, leukocytosis, peripheral blasts $\geq 1 \%$ and constitutional symptoms [11]. The IPSS was subsequently adjusted for the time-dependent estimation of survival [12], and platelet count less than $100 \times 10^{9} / \mathrm{L}$, red cell transfusion dependence, and unfavorable karyotype were included as additional risk factors [13]. However, this still limited list of clinical risk factors validated in PMF does not consider the prognostic significance of comorb.i.d.ity index [14,15], circulating levels of specific cytokines [16], bone marrow fibrosis grade $[14,17,18]$, or mutation status $[19,20]$.

The pathogenesis of MF is complex and heterogeneous. A key disease mechanism at multiple stages of MF pathogenesis is the dysregulation of JAK-STAT signaling, which is a hallmark of MPNs regardless of somatic mutations and clinical characteristics [21]. JAK2 plays a critical role in the regulation of hematopoiesis as an intracellular mediator of incoming signals from hematopoietic cytokines [22]. Somatic mutations, including mutations in $J A K 2, M P L$ and $C A L R$, result in overactivation of JAK2 signaling and uncontrolled malignant stem cell replication [21]. Moreover, dysregulated JAK-STAT signaling is manifested in abnormally high circulating levels of pro-inflammatory cytokines [16,23], many of which signal directly through JAK1 [22].The JAK2V617F mutation occurs in approximately $50-60 \%$ of cases of MF. Patients with MF lacking this mutation are now recognized to generally have mutations in either MPL (5-10\%) or CALR (the majority of patients with wild-type $J A K 2$ ), mutations that have also been implicated in the aberrant activation of JAK-STAT signaling [24-26]. The mutation profile is clinically relevant as patients with $C A L R$ mutations appear to have higher platelet counts and longer survival than patients with $J A K 2$ mutations [27]. Finally, patients with 'triple negative' MF carry a diverse range of mutations and appear to constitute the group of patients with the worst prognosis [27-30]. Specifically, ASXL1, EZH2, CBL, IDH1/IDH2, TP53, SRSF2 and IDH1/2 mutations have been associated with increased risk of disease progression and leukemic transformation and/or shortened survival [19,20].

\section{Overview of the market}

Currently, only allogeneic stem cell transplantation has the potential to eliminate neoplastic stem cell clones and consequently cure patients with MF. However, given the need for appropriate donors and the high risks of treatment failure and treatment-related mortality associated with the procedure, few patients are eligible for allogeneic stem cell transplantation [31]. Because of the central role of overactive JAK-STAT signaling in both MPN pathogenesis and MF-associated systemic inflammation, JAK inhibitors have become 
the preferred drug class for the development of MF-targeted pharmacotherapy. Ruxolitinib (Jakafi®, Incyte Corporation; JAKAVI ${ }^{\circledR}$, Novartis Pharmaceuticals), a JAK 1 and JAK 2 inhibitor, was approved in the United States in November 2011 for the treatment of patients with intermediate- or high-risk MF [32]. Approval was based on the positive results of two Phase III clinical trials, the double-blind COMFORT-I trial, which compared the efficacy and safety of ruxolitinib versus placebo, and the open-label COMFORT-II study, which compared ruxolitinib versus best available therapy (BAT) [33,34]. Two other JAK inhibitors, pacritinib (NCT02055781) and momelotinib (NCT02101268, NCT01969838), are currently in Phase III clinical development for MF, and the highly selective JAK2 inhibitor fedratinib recently demonstrated efficacy in a placebo-controlled Phase III study [35]. However, fedratinib was subsequently discontinued, because its use was linked to cases of Wernicke's encephalopathy, a serious neurological disease associated with thiamine deficiency [36]. New evidence shows that fedratinib is a strong inhibitor of thiamine absorption in vitro, likely as a consequence of its unique structural similarity with thiamine [37]. Wernicke's encephalopathy has not been reported for any other JAK inhibitors, including ruxolitinib. Another potent JAK2 inhibitor, XL019, recently was terminated in Phase I because of its association with central and peripheral neuropathy [38].

Ongoing clinical development of therapies that may expand the armamentarium for the treatment of MF and further improve outcomes include trials combining ruxolitinib with buparlisib (PI3K inhibitor), panobinostat (histone deacetylase inhibitor), LDE225 (hedgehog inhibitor), PRM-151 (recombinant human pentraxin-2), GS-6624 (monoclonal antibody against lysyl oxidase-like-2) or antianemia agents. In addition, there is preliminary evidence (requiring confirmation in randomized controlled clinical trials) that pegylated IFN-a-2a may induce hematologic remission (including anemia response) and symptom improvement in patients with MF [39,40], and in a few cases partial molecular response has been observed with long-term IFN-a therapy [41,42].

\section{Chemistry}

Ruxolitinib, (R)-3-(4-(7H-pyrrolo[2,3-d]pyrimidin-4-yl)-1H-pyrazol-1-yl)-3cyclopentylpropanenitrile phosphate, has a molecular weight of $404.36 \mathrm{kDa}$. Ruxolitinib is soluble in aqueous solutions at $\mathrm{pH} 1-8$. Ruxolitinib tablets are stable at $20-25^{\circ} \mathrm{C}$ and tolerate brief exposures to temperatures outside this range, if they stay within $15-30^{\circ} \mathrm{C}$ [32].

\section{Pharmacokinetics \& pharmacodynamics}

Single doses of ruxolitinib administered orally to healthy volunteers were absorbed rapidly, with times to maximum serum concentration of $\mathcal{S} \mathrm{h}$ [43]. Ruxolitinib exhibited doseproportional exposure for doses ranging from 5 to $200 \mathrm{mg}$ [43]. Bioavailability of orally administered ruxolitinib (25-mg tablets) was not significantly affected by concomitant food intake [43]; however, absorption of ruxolitinib was slower when the drug was taken together with a high-fat, high-calorie meal. Overall, the data indicate that ruxolitinib may be taken with or without food. 
Ruxolitinib has a short terminal half-life of approximately $3 \mathrm{~h}$ for doses up to $100 \mathrm{mg}$ [43], suggesting that twice-daily (b.i.d.) administration of ruxolitinib is preferable to once-daily dosing. In a multiple-dosing study in healthy volunteers, steady-state concentrations were reached by day 2 , with negligible drug accumulation [43]. At steady-state, oral ruxolitinib exhibited a dose-independent clearance of approximately $20 \mathrm{l} / \mathrm{h}$ and a volume of distribution of 77 and 801 for doses of 15 and $25 \mathrm{mg}$ every $12 \mathrm{~h}$, respectively [43].

A population pharmacokinetic analysis in 414 patients with MF who participated in the ruxolitinib Phase II and III trials identified gender as the only covariate for oral clearance, with estimated values of 22.1 and $17.7 \mathrm{l} / \mathrm{h}$ for male and female patients, respectively, with a $39 \%$ interindividual variability [44]. Body weight was the only covariate for the volume of distribution for the central compartment. However, further analysis suggested that gender and body weight had no clinically significant effects on ruxolitinib pharmacokinetics that should prompt dose adjustments [44].

Ruxolitinib is metabolized by CYP3A4 and to a lesser extent by CYP2C9. Fluconazole, an inhibitor of both CYP3A4 and CYP2C9, is predicted to increase ruxolitinib plasma exposure by 100-300\% [32]. Concomitant administration of a potent CYP3A4 inhibitor (ketoconazole) resulted in a 91\% increase in ruxolitinib plasma exposure [45]. Consequently, as detailed in the USA prescribing information [32], a 50\% reduction in starting and maintenance doses is recommended for patients who are taking ruxolitinib in combination with a potent CYP3A4 inhibitor or fluconazole $\_00 \mathrm{mg}$ and, for patients using a stable dose of $5 \mathrm{mg}$ once daily, concomitant use of a potent CYP3A4 inhibitor or fluconazole should be avoided. If used concomitantly with ruxolitinib, the dose of fluconazole should not exceed $200 \mathrm{mg}$ daily [32].

In a multiple-dosing study in healthy volunteers, ruxolitinib exhibited ex vivo inhibition of cytokine-induced pSTAT3 with a concentration at half-maximal inhibition $\left(\mathrm{IC}_{50}\right)$ of $225 \mathrm{nM}$. In addition, ruxolitinib administration caused slight reductions in absolute reticulocyte and neutrophil counts at a dose of $25 \mathrm{mg}$ b.i.d. [43].

\section{Patients with hepatic or renal impairment}

Ruxolitinib exposure was increased by 87,28 and $65 \%$ in patients $(n=24)$ with mild, moderate and severe hepatic impairment, respectively, compared with healthy volunteers (n $=8$ ); no correlation was observed between exposure of ruxolitinib and the degree of hepatic impairment [46]. In a study of ruxolitinib in volunteers with $(n=32)$ or without $(n=8)$ renal impairment, no effect of renal impairment on ruxolitinib pharmacokinetics was noted; however, pharmacologic activity increased with increasing severity of renal impairment due to an increase in the serum concentrations of active metabolites [46].

\section{Pregnant women \& nursing mothers}

The effects of ruxolitinib in pregnant women and nursing mothers are currently unknown because of the lack of pertinent clinical studies. Animal studies suggest that ruxolitinib has no teratogenic effects but may decrease fetal weight at high concentrations. In addition, ruxolitinib and/or its metabolite have been shown to be excreted in the milk of lactating rats [32]. 


\section{Preclinical studies}

Ruxolitinib is an equipotent inhibitor of JAK1 and JAK2, with in vitro $\mathrm{IC}_{50}$ values (mean \pm standard deviation) of $3.3 \pm 1.2 \mathrm{nM}$ and $2.8 \pm 1.2 \mathrm{nM}$, respectively, and with sixfold and greater than 100-fold selectivity against Tyk3 and JAK3, respectively [47]. Ruxolitinib showed strong inhibition of IL-6 signaling $\left(\mathrm{IC}_{50}=281 \mathrm{nM}\right)$ and proliferation of $J A K 2 \mathrm{~V} 617 \mathrm{~F}$-positive $\mathrm{Ba} / \mathrm{F} 3$ cells $\left(\mathrm{IC}_{50}=127 \mathrm{nM}\right)$ and effectively suppressed erythroid progenitor colony formation in primary cultures from patients with $\mathrm{PV}\left(\mathrm{IC}_{50}=67 \mathrm{nM}\right)$ compared with those from healthy donors $\left(\mathrm{IC}_{50}>400 \mathrm{nM}\right)$. In a mouse model of JAK2V617F-positive MPN, oral ruxolitinib markedly reduced splenomegaly and circulating levels of the pro-inflammatory cytokines IL-6 and tumor necrosis factor-a and significantly prolonged survival. In this mouse model, ruxolitinib preferentially eliminated neoplastic (JAK2V617F-positive) cells and had no notable myelosuppressive or immunosuppressive effects [47].

\section{Clinical efficacy}

Phase I/II

The safety and efficacy of ruxolitinib in patients with MF was first evaluated in a two-center Phase I/II study in 153 patients with advanced PMF, post-PV MF or post-ET MF [23]. The initial dose-escalation Phase established $25 \mathrm{mg}$ b.i.d. or $100 \mathrm{mg}$ once daily as the maximum tolerated doses, with thrombocytopenia as the dose-limiting toxicity. A starting dose of 15 $\mathrm{mg}$ b.i.d. combined with individualized dose titration to maximize response and limit the risk of thrombocytopenia was associated with the most favorable benefit/risk ratio. In this dosage group, 17 out of 33 patients (52\%) experienced a rapid $250 \%$ reduction of splenomegaly, which was maintained in $73 \%$ of the responders after 12 months of therapy [23]. Three patients with MF who developed hepatomegaly after splenectomy achieved significant reductions in liver size and hepatomegaly-related symptoms [48].

In addition to the alleviation of hepatosplenomegaly, ruxolitinib had a major impact on MFrelated symptom burden. At 6 months, 88, 82, 55 and $40 \%$ of symptomatic patients who received ruxolitinib $10-25 \mathrm{mg}$ b.i.d. had a $250 \%$ improvement in symptom scores for night sweats, itching, abdominal pain or discomfort and bone or muscle pain, respectively [23].

Long-term follow-up data from one of the two centers that participated in the Phase I/II study showed that some patients experienced stabilization or regression of bone marrow fibrosis. After 5 years of treatment with ruxolitinib, 35 and $42 \%$ of patients $(n=26)$ had improved or stabilized bone marrow fibrosis relative to baseline assessment, respectively, compared with 3 and 28\% ( $\mathrm{n}=32)$ of patients with PMF from a historical control group who received conventional therapies [49]. In addition, complete resolution of bone marrow fibrosis with ruxolitinib after treatment periods of 39 and 17 months has been reported for two cases of post-PV MF in clinical practice [50,51].

\section{The Phase III COMFORT studies}

COMFORT-I was a randomized placebo-controlled study of 309 patients with IPSS intermediate- 2 or high-risk MF and a platelet count $\geq 100 \times 10^{9} / 1$ [33]. The starting dose of 
ruxolitinib was $15 \mathrm{mg}$ B.I.D. for patients with baseline platelet counts of $100-200 \times 10^{9} / 1$ and $20 \mathrm{mg}$ b.i.d. for those with baseline platelet counts more than $200 \times 10^{9} / 1$. The primary end point was the proportion of patients who had a $235 \%$ reduction in spleen volume (measured by magnetic resonance imaging or computed tomography) from baseline to week 24 . A $35 \%$ reduction in spleen volume corresponds approximately to a $50 \%$ reduction in palpable spleen length. The results are summarized in Table 1 . The proportion of patients who reached the primary end point was $41.9 \%$ in the ruxolitinib arm compared with $0.7 \%$ in the placebo arm $(\mathrm{p}<0.001)$. Of the 155 patients randomized to ruxolitinib, $150(96.8 \%)$ experienced some degree of spleen volume reduction. By contrast, 102 out of $153(66.7 \%)$ patients in the placebo arm experienced worsening of splenomegaly and 15 out of 153 (9.8\%) experienced no change [33].

A total of $45.9 \%$ of patients in the ruxolitinib arm versus $5.3 \%$ of patients in the placebo arm had a $250 \%$ reduction in total symptom score (as assessed with the modified Myelofibrosis Symptom Assessment Form, version 2.0) from baseline to week 24 ( $p$ < 0.001) [33]. In addition, patients in the ruxolitinib versus the placebo arm experienced significant alleviation of fatigue as well as improvement in global health status/quality of life (QoL) and in physical, role, emotional, and social functioning $(\mathrm{p}<0.001)$ assessed with the European Organisation for Research and Treatment of Cancer Quality of Life 30 Questionnaire (EORTC QLQ-C30) [33]. COMFORT-I subgroup analyses further showed that the efficacy of ruxolitinib therapy in terms of spleen size reduction and symptom alleviation was preserved in subgroups defined by age, MF subtype, IPSS risk status, European Cooperative Oncology Group performance status, spleen length, hemoglobin level, platelet count or $J A K 2$ V617F mutation status at baseline [54]. Post hoc analyses showed that ruxolitinib therapy was associated with symptom and QoL improvements even in patients with no clinically significant $(<10 \%)$ spleen volume reduction [55]. At the time of the primary analysis, three (1.9\%) patient in the ruxolitinib arm and 12 (7.8\%) patients in the placebo arm discontinued because of disease progression [33].

In COMFORT-II, 219 patients with IPSS intermediate- 2 or high-risk MF and a platelet count $\geq 100 \times 10^{9} / 1$ were randomized to ruxolitinib or best BAT at a ratio of 2:1 [34]. As in

COMFORT-I the starting dose of ruxolitinib was 15 or $20 \mathrm{mg}$ b.i.d. for patients with baseline platelet counts of $100-200 \times 10^{9} / 1$ and $>200 \times 10^{9} / 1$, respectively. The primary endpoint, which was the proportion of patients who achieved a $235 \%$ spleen volume reduction at week 48 , was achieved by $28 \%$ of the patients in the ruxolitinib arm versus $0 \%$ in the BAT arm (p $<0.001$ ) (Table 1). Spleen volume responses (i.e., $235 \%$ reduction from baseline at week 48) were not significantly different across subgroups defined by gender, age, starting dose, $J A K 2 \mathrm{~V} 617 \mathrm{~F}$ mutation status at baseline, MF type, IPSS risk category or spleen length at baseline [56]. Compared with BAT, ruxolitinib treatment was also associated with clinically significant improvement in EORTC QLQ-C30 measures for QoL and MF-related symptoms, including role functioning, fatigue, dyspnea, insomnia and appetite loss [34,57]. At the time of the primary analysis, one $(0.7 \%)$ patient in the ruxolitinib arm and three $(4.1 \%)$ patients in the BAT arm had discontinued because of disease progression [34].

Patients in both COMFORT studies had the option to crossover from the control to the ruxolitinib arm according to protocol-defined criteria for worsening splenomegaly. This 
resulted in progressive attrition of the study population in the control arms, with a median time to crossover of 41 weeks in COMFORT-I [58] and 75 weeks in COMFORT-II [Vannucchi AM et al. A pooled analysis of overall survival in COMFORT-I and COMFORTII, two randomized Phase 3 trials of ruxolitinib for the treatment of myelofibrosis (2015), submitted]. Consequently, efficacy analyses conducted after the primary analyses were largely limited to the ruxolitinib arms. Out of the 155 patients originally randomized to ruxolitinib in COMFORT-I, 64.5 and $49.7 \%$ were still on therapy at median follow-up times of 102 and 149 weeks, respectively, with median reductions from baseline in spleen volume of $34.9 \%$ at week 96 and $34.1 \%$ at week 144 [52,58]. In total, 59\% of patients in the ruxolitinib arm had a $235 \%$ spleen volume reduction at any time during follow-up, and those patients had a 53\% probability of maintaining their response for at least 132 weeks [52]. In addition, QoL improvements from baseline seen in the primary analysis were generally maintained with continued therapy [58]. In COMFORT-II, 51\% of patients in the ruxolitinib arm had a $235 \%$ spleen volume reduction and a $50 \%$ probability of maintaining this response at week 144 [53]. Together, the results from COMFORT-I and COMFORT-II indicate that ruxolitinib-mediated reductions in splenomegaly and symptom burden not only occurred rapidly but also were generally durable in patients who received chronic therapy.

In both COMFORT studies, ruxolitinib was effective in patients with and without the $J A K 2 \mathrm{~V} 617 \mathrm{~F}$ mutation [33,34,54]. In COMFORT-I, ruxolitinib therapy in patients with the $J A K 2 \mathrm{~V} 617 \mathrm{~F}$ mutation resulted in a mean spleen volume reduction of $34.6 \%$ at week 24 compared with an $8.1 \%$ increase with placebo [33]. In patients without the $J A K 2 \mathrm{~V} 617 \mathrm{~F}$ mutation, ruxolitinib resulted in a mean spleen volume reduction of $23.8 \%$ whereas an $8.4 \%$ increase was seen with placebo. JAK2V617F positive patients also experienced a $52.6 \%$ improvement in TSS with ruxolitinib compared with a $42.8 \%$ worsening in the placebo arm. For $J A K 2 \mathrm{~V} 617 \mathrm{~F}-$ negative patients, the corresponding changes were $28.1 \%$ improvement with ruxolitinib and $37.2 \%$ worsening with placebo [33]. Moreover, a post hoc COMFORTII analysis found that spleen and symptom responses were similar among patients with different mutation profiles [59]. The efficacy of ruxolitinib in patients without the $J A K 2 \mathrm{~V} 617 \mathrm{~F}$ mutation is consistent with evidence that overactive JAK-STAT signaling is a central pathogenic defect in MF, irrespective of mutational background $[21,60]$.

In the COMFORT studies, ruxolitinib treatment led to modest reductions in JAK2V617F allele burden, and these reductions had a tendency to become gradually more pronounced over time [33,53]. Patients in the ruxolitinib arm of COMFORT-I had mean reductions in $J A K 2 \mathrm{~V} 617 \mathrm{~F}$ allele burden of 10.9 and $21.5 \%$ at weeks 24 and 48 , respectively, compared with corresponding mean increases of 3.5 and $6.3 \%$ in the placebo arm [33]. In COMFORTII, ruxolitinib therapy was associated with a $7 \%$ median decrease in allele burden at week 48 compared with no change in the BAT arm [53]. Overall, these numbers suggest that the clinical efficacy of ruxolitinib does not require a highly effective suppression of mutant clonal proliferation.

\section{Survival in the COMFORT studies}

Results from the COMFORT trials showed that ruxolitinib improves clinical risk factors with established or potential prognostic significance, including splenomegaly, symptom 
burden, pro-inflammatory cytokine levels, unwanted weight loss and hypocholesterolemia [33,34,61]. Consistent with these observations, various survival analyses in the COMFORT trials have shown a moderate survival advantage in favor of patients originally randomized to ruxolitinib versus patients originally randomized to placebo or BAT (Table 2, $[33,34,52,53,58,62,63])$. This survival advantage based on intention-to-treat analysis was observed consistently despite the continuing crossover to ruxolitinib treatment in the control arms, which may have had a positive effect on survival in the control arms. A survival analysis of pooled data from the COMFORT trials at a median follow-up of approximately 3 years estimated a $35 \%$ reduction in the risk of death for patients randomized to ruxolitinib compared with those randomized to placebo or BAT (Table 2), with baseline splenomegaly as a significant negative prognostic factor [63]. In COMFORT-II, the survival advantage observed with ruxolitinib versus BAT was independent of the mutation profile and was maintained in patients with prognostically detrimental mutations (Table 2) [59].

Furthermore, a comparison of COMFORT-II data with those from a historical control group by multivariate regression analysis yielded a hazard ratio of 0.64 (95\% CI: : 0.4-0.96, p = 0.034 ) in favor of ruxolitinib after adjustment for age at diagnosis and IPSS risk at the time of analysis [64].

\section{Other clinical studies}

Two multicenter open-label clinical studies of ruxolitinib were or are being conducted in patients with MF and low platelet counts $\left(50-100 \times 10^{9} / 1\right)$, a population that was excluded from the COMFORT studies [65,66]. In a Phase II study conducted in 50 patients with intermediate- or high-risk MF and low platelet counts, ruxolitinib was initiated at a dose of 5 $\mathrm{mg}$ b.i.d., with the option to increase doses by $5 \mathrm{mg}$ once daily every 4 weeks to a maximum of $10 \mathrm{mg}$ b.i.d., provided that platelet counts remained adequate. Higher doses (up to $15 \mathrm{mg}$ b.i.d.) were permitted only for patients with adequate platelet counts and lack of response. In an interim analysis, $62 \%$ of patients evaluable for dosing $(n=41)$ achieved stable doses $\geq 10$ $\mathrm{mg}$ b.i.d. by week 24. Median reductions in spleen volume and TSS in patients who completed 24 weeks of therapy with evaluable data were $24.2 \%(n=30)$ and $43.8 \%(n=$ 32 ), respectively. Out of 40 patients evaluable for spleen volume responder analyses, $20 \%$ had a $>35 \%$ spleen volume reduction and $52.5 \%$ had a $\geq 10 \%$ spleen volume reduction [65].

An ongoing Phase Ib dose-finding study (EXPAND) seeks to determine the maximum safe starting doses of ruxolitinib for patients with baseline platelet counts of $75-99 \times 10^{9} / 1$ (stratum 1) and those with platelet counts of 50-74 $\times 10^{9} / 1$ (stratum 2) [66]. Interim results in 12 patients who completed more than 28 days of treatment revealed no dose-limiting toxicities for a dose of $10 \mathrm{mg}$ b.i.d. in stratum 1 and for a dose of $5 \mathrm{mg}$ b.i.d. in stratum 2. In all 12 patients, ruxolitinib treatment was associated with reductions in palpable spleen length, including complete resolution of splenomegaly in three patients [66].

Although the pivotal Phase III COMFORT trials did not include patients with intermediate-1-risk MF, recent results of a multicenter open-label study in the United Kingdom of 48 patients with intermediate-1, intermediate-2 or high-risk MF showed that spleen and symptom responses at week 24 were similar across all risk categories [67]. 
A small study evaluated the effects of ruxolitinib on pulmonary hypertension in 15 patients with intermediate- or high-risk MF [68]. Treatment over periods ranging from 4 to 18 months resulted in improved echocardiographic findings, including significant reductions in right ventricular systolic blood pressure, compared with baseline values in $66 \%$ of the patients $(\mathrm{p}=0.022)$. Ruxolitinib therapy also led to a more than $50 \%$ increase in plasma nitric oxide levels in seven patients (46\%), and the majority of patients had reductions in the levels of serum biomarkers for pulmonary hypertension, including N-terminal pro-hormone of brain natriuretic peptide (73\%), von Willebrand antigen (86\%), ristocetin-cofactor activity (73\%) and uric acid (60\%) [68].

Clinical development of ruxolitinib for the treatment of patients with PV who have had inadequate response to or are intolerant of hydroxyurea recently yielded encouraging results in Phase II [69] and Phase III [70]. Results of the pivotal Phase III RESPONSE trial, which enrolled 222 patients, showed that ruxolitinib compared with BAT was associated with a significant increase at week 32 in the proportion of patients who achieved both hematocrit control (defined as $\leq$ phlebotomy in the first 8 weeks after randomization and no eligibility for phlebotomy based on hematocrit levels from weeks $8-32$ ) and a $235 \%$ reduction from baseline in spleen volume ( 21 versus $1 \%, \mathrm{p}<0.0001$ ) [70]. Ruxolitinib versus BAT also provided improvement for other end points during the first 32 weeks, including achievement of hematocrit control (60 vs $20 \%$ ), $235 \%$ spleen volume reduction (38 vs 1\%), $250 \%$ symptom improvement (49 vs 5\%), and complete hematologic response (24 vs 9\%). Grade 3 or 4 anemia (1.8 vs $0 \%$ ) and thrombocytopenia (5.5 and 3.6\%) were more common with ruxolitinib than BAT [70].

\section{Experience in clinical practice}

Experience from compassionate use programs as well as retrospective studies conducted in the United States at single institutions after the approval of ruxolitinib by the US FDA confirmed the clinical benefits of ruxolitinib established in the COMFORT studies [71-75]. In a study conducted at Mayo Clinic, Scottsdale, AZ, USA, 36\% of 22 patients with MF treated with ruxolitinib experienced complete resolution of palpable splenomegaly at a median follow-up of 72 days. In addition, large proportions of the patients experienced improvement of MF-related symptoms, including fatigue (75\%), early satiety (71\%), night sweats (53\%), abdominal pain (71\%), pruritus (56\%), weight loss (69\%), bone pain (33\%) and fevers (33\%) [75].

Consistent with results of the COMFORT studies, a recent study in 41 consecutive patients with MF treated with ruxolitinib in clinical practice found that only four patients experienced primary clinical resistance to ruxolitinib, as they failed to achieve a spleen volume reduction greater than $10 \%$. However, loss of spleen response was observed in 12 patients [76]. It remains unclear how clinical resistance relates to possible molecular mechanisms of resistance [77] or persistence [78]. Persistence has been described as a reversible mechanism of circumventing JAK2 inhibition through transactivation of JAK2 by other JAK kinases. Persistence against ruxolitinib could be reversed by temporary withdrawal of ruxolitinib in vitro and in vivo [78]. Reversal of persistence also may account for the restoration of ruxolitinib treatment response after brief withdrawal in two patients 
with MF treated in clinical practice [79]. In one case, a patient with PMF who had become nonresponsive even to high doses of ruxolitinib ( $20 \mathrm{mg}$ b.i.d.) over a period of months rapidly regained spleen response with a dose of $5 \mathrm{mg}$ b.i.d. after a gradual withdrawal period of 2 weeks followed by 2 days without therapy [79].

\section{Safety \& tolerability}

\section{Hematologic effects}

Given the essential function of JAK2 in mediating signals from erythropoietin and thrombopoietin, dose-dependent anemia and thrombocytopenia are expected adverse effects of ruxolitinib therapy. In the COMFORT studies, anemia and thrombocytopenia were the most common adverse events (Table 3) but rarely resulted in treatment discontinuation $[33,34]$. Cytopenias, which occurred mostly during the first 3 months of therapy in COMFORT-I, were generally managed with dose adjustments and/or brief treatment interruptions and red blood cell transfusions (for anemia) [80]. As a result, following the initial decreases, platelet counts tended to stabilize after 8-12 weeks of treatment, and hemoglobin levels returned close to baseline values by week 20 [80]. At week 12, patients with baseline platelet counts of 100-200 $\times 10^{9} / 1$ experienced a mean decrease in hemoglobin of approximately $10 \%$ and patients with platelet counts greater than $200 \times 10^{9} / 1$ had a mean decrease of approximately $12 \%$ [80]. Out of 50 patients enrolled in a Phase II study of ruxolitinib in patients with MF and platelet counts of 50-100 $\times 10^{9} / 1,24 \%$ required dose reductions because of decreases in platelet counts to levels less than 35 and $25 \times 10^{9} / \mathrm{l}$, and $8(16 \%)$ patients experienced grade 4 thrombocytopenia, resulting in one discontinuation [65].

\section{Ruxolitinib dosing recommendations}

The starting dose of ruxolitinib in the COMFORT studies was $15 \mathrm{mg}$ b.i.d. for patients with baseline platelet counts of $100-200 \times 10^{9} / \mathrm{L}$ and $20 \mathrm{mg}$ b.i.d. for those with baseline platelet counts more than $200 \times 10^{9} / 1[33,34]$. Across both trials, $65 \%$ of those who started ruxolitinib treatment at $15 \mathrm{mg}$ b.i.d. and $25 \%$ of those who started at $20 \mathrm{mg}$ b.i.d. had dose reductions within the first 8 weeks of therapy [32]. Based on the COMFORT experience, specific recommendations for starting doses and dose modifications in patients with platelet counts $\geq 100 \times 10^{9} / 1$ were incorporated in the US prescribing information for ruxolitinib (Table 4) [32]. In addition, based on pharmacokinetics and pharmacodynamics data (see the 'Pharmacokinetics \& pharmacodynamics' section), a reduced starting dose (10 mg b.i.d.) is recommended for patients with any degree of hepatic impairment or with moderate or severe renal impairment who have a platelet count of $100-150 \times 10^{9} / 1$. For patients with end stage renal disease on dialysis, 15 or $20 \mathrm{mg}$ once after dialysis is recommended as the starting dose if the platelet count is $100-200 \times 10^{9} / 1$ or more than $200 \times 10^{9} / 1$, respectively. Ruxolitinib should be avoided for patients with end stage renal disease not requiring dialysis or with moderate or severe renal impairment or hepatic impairment and a platelet count less than $100 \times 10^{9 / 1}[32]$.

An analysis of dosing in COMFORT-I further showed that most patients in the ruxolitinib arm achieved final titrated doses $\geq 10 \mathrm{mg}$ b.i.d. For many patients, $10 \mathrm{mg}$ b.i.d. appeared to 
be an appropriate maintenance dose, as the treatment benefit at week 24 in terms of median reductions in spleen size and symptom burden was similar for patients who received final titrated doses of $10 \mathrm{mg}$ b.i.d. and those who received higher doses [80]. For patients with platelet counts of $50-100 \times 10^{9} / 1$, gradual up-titration from a starting dose of $5 \mathrm{mg}$ b.i.d. is recommended (Table 5) [32] based on the interim results of a Phase II study [65]. Most patients in this study were able to achieve final titrated doses $\geq 10 \mathrm{mg}$ b.i.d. [65].

\section{Nonhematologic effects}

Aside from the previously discussed hematologic effects, in the COMFORT-I primary safety analysis, few adverse events, including ecchymosis, dizziness, headache and urinary tract infections (Table 6), were more common with ruxolitinib than with placebo and those were almost exclusively low grade [32,33]. Ruxolitinib was also associated with increased rates of new or worsening grade 1 abnormalities in alanine transaminase (ALT, 25.2 vs 7.3\%) and aspartate transaminase (AST, 17.4 vs $6.0 \%$ ) versus placebo. However, few patients in the ruxolitinib arm developed grade $\geq 2$ ALT (1.9\%, with $1.3 \%$ grade 3, no grade 4) or AST ( $0.6 \%$, with no grade 3 or 4$)$ elevation [32]. Neither COMFORT trial reported unexpected safety concerns over a 3 -year follow-up period [52,53,58].

Nonclinical and clinical data suggest that ruxolitinib has immunosuppressive effects, including downregulation of Tregs and impairment of dendritic cell function [81-83]. Although such effects may have played a role in isolated cases of serious opportunistic infections in patients on ruxolitinib therapy, including progressive multifocal leukoencephalopathy (PML) [84], reactivation of hepatitis B virus [85], pneumonia [86], disseminated tuberculosis [87], reactivation of herpes simplex virus [88] and Pneumocystis jiroveci pneumonitis [89], the relationship of these infections with ruxolitinib treatment remains unclear. Common infections that occurred during randomized treatment in patients in the ruxolitinib arm of COMFORT-I were urinary tract infections and herpes zoster (Table 6) [32]. In our experience, antimicrobial prophylaxis is not required for most patients with MF who are treated with ruxolitinib, although increased vigilance for opportunistic infections is recommended.

MF-related symptoms generally return within 1 week after cessation of ruxolitinib therapy [32]. Although serious adverse events associated with treatment discontinuation or interruption in COMFORT-I were similar for ruxolitinib and placebo [33,58], five patients who participated in the ruxolitinib Phase I/II study have been reported to experience fever, hypotension, respiratory distress, and/or disseminated intravascular coagulation after ruxolitinib treatment discontinuation [90]. However, no case of "withdrawal syndrome" has been reported in the Phase III COMFORT studies [33,34]. If ruxolitinib therapy needs to be interrupted or permanently discontinued for reasons other than thrombocytopenia or neutropenia, gradual tapering of the ruxolitinib dose may be preferable to abrupt treatment cessation [32].

\section{Regulatory affairs}

In the USA, ruxolitinib is approved for the treatment of patients with intermediate or highrisk PMF, post-PV MF or post-ET MF [32]. In addition, ruxolitinib recently has been 
approved for the treatment of patients with PV who have had an inadequate response to or are intolerant of hydroxyurea, based on the results of Phase II and III clinical studies $[69,70]$.

In Canada, ruxolitinib is approved for the treatment of splenomegaly and/or its associated symptoms in adult patients with PMF, post-PV MF or post-ET MF [91]. In the EU, ruxolitinib is approved for disease-related splenomegaly and symptoms in adult patients with PMF, post-PV MF or post-ET MF [92,93]. To date, ruxolitinib has been approved for indications in $\mathrm{MF}$ in 83 countries.

Product monographs and prescribing information for various countries, including the USA contain precautions and warnings to assess the risk of developing serious bacterial, mycobacterial, fungal or viral infections, to resolve serious infections before starting therapy and to withhold therapy for patients who have PML [32,91-92]. In the USA, therapy should also be stopped if PML is suspected, and the patient should undergo further evaluation [32]. In Canada, ruxolitinib is explicitly contraindicated for patients with current or previous PML [91]. European prescribing information indicates that ruxolitinib should not be given to patients with active tuberculosis infections, and Canadian prescribing information indicates it should not be given to patients with tuberculosis infections [91,93]. The US prescribing information cautions that starting ruxolitinib therapy in patients with latent or active tuberculosis should be decided in consultation with a specialist in the treatment of tuberculosis, and continuation of therapy in patients with active tuberculosis should be based on overall risk-benefit determination [32]. There are no contraindications for ruxolitinib in the USA [32].

Pregnancy and lactation are contraindications for the use of ruxolitinib per the European prescribing information [93]. The Canadian prescribing information recommends that women avoid the use of ruxolitinib if pregnant and that they do not breastfeed if they are taking ruxolitinib [91]. In the USA, ruxolitinib should be taken by pregnant women only if the benefit outweighs the risk and concurrent breastfeeding and ruxolitinib therapy are not recommended [32].

\section{Conclusion}

Ruxolitinib, a JAK1 and JAK2 inhibitor, is currently the only approved pharmacotherapy that has been shown in randomized controlled trials to be efficacious and safe in the treatment of patients with MF. Ruxolitinib is highly effective in reducing splenomegaly and improving MF-related symptoms and QoL measures. In addition, survival analyses from the Phase III studies overall suggest that ruxolitinib therapy is associated with a survival advantage compared with placebo or BAT. Ruxolitinib on average causes moderate reductions in mutant allele burden, suggesting that it has no major impact on the proliferation of mutant stem cell clones. However, improvement of mutant allele burden is not a prerequisite for clinical efficacy, which is independent of mutational background. Dose-dependent thrombocytopenia and anemia are expected and common. They require careful dosing management consistent with ruxolitinib prescribing information to ensure continuing uninterrupted therapy, which is key to maintaining treatment benefit. Because 
ruxolitinib has immunosuppressive properties, precautions should be taken to prevent serious and potentially fatal infections. These precautions should include thorough pretreatment screening for infections and delaying treatment initiation or stopping treatment with ruxolitinib in cases of active unresolved infections.

\section{Acknowledgments}

CS Tam received honorarium from Novartis. S Verstovsek received research funding from Incyte, AstraZeneca, Lilly Oncology, Geron, NS Pharma, Bristol-Myers Squibb, Novartis, Celgene, Gilead, Seattle Genetics, Promedior, and Cell Therapeutics.

Medical writing assistance was provided by Roland Tacke, PhD, CMPP, of Evidence Scientific Solutions and funded by Incyte Corporation.

\section{References}

Papers of special note have been highlighted as:

- of interest; $\bullet$ of considerable interest

1. Mesa RA, Green A, Barosi G, Verstovsek S, Vardiman J, Gale RP. MPN-associated myelofibrosis (MPN-MF). Leuk. Res. 2011; 35(1):12-13. [PubMed: 20684988]

2. Vardiman JW, Thiele J, Arber DA, et al. The 2008 revision of the World Health Organization (WHO) classification of myeloid neoplasms and acute leukemia: rationale and important changes. Blood. 2009; 114(5):937-951. [PubMed: 19357394]

3. Barosi G, Mesa RA, Thiele J, et al. Proposed criteria for the diagnosis of post-polycythemia vera and post-essential thrombocythemia myelofibrosis: a consensus statement from the International Working Group for Myelofibrosis Research and Treatment. Leukemia. 2008; 22(2):437-438. [PubMed: 17728787]

4. Tefferi A. Primary myelofibrosis: 2013 update on diagnosis, risk-stratification, and management. Am. J. Hematol. 2013; 88(2):141-150. [PubMed: 23349007]

5. Tefferi A. Polycythemia vera and essential thrombocythemia: 2013 update on diagnosis, riskstratification, and management. Am. J. Hematol. 2013; 88(6):507-516. [PubMed: 23695894]

6. Tefferi A, Lasho TL, Jimma T, et al. One thousand patients with primary myelofibrosis: the Mayo Clinic experience. Mayo Clin. Proc. 2012; 87(1):25-33. [PubMed: 22212965]

7. Gregory SA, Mesa RA, Hoffman R, Shammo JM. Clinical and laboratory features of myelofibrosis and limitations of current therapies. Clin. Adv. Hematol. Oncol. 2011; 9(9 Suppl 22):1-16. [PubMed: 22362131]

8. Mesa RA, Niblack J, Wadleigh M, et al. The burden of fatigue and quality of life in myeloproliferative disorders (MPDs): an international Internet-based survey of 1179 MPD patients. Cancer. 2007; 109(1):68-76. [PubMed: 17123268]

9. Mesa RA, Schwager S, Radia D, et al. The Myelofibrosis Symptom Assessment Form (MFSAF): an evidence-based brief inventory to measure quality of life and symptomatic response to treatment in myelofibrosis. Leuk. Res. 2009; 33(9):1199-1203. [PubMed: 19250674]

10. Mesa RA, Shields A, Hare T, et al. Progressive burden of myelofibrosis in untreated patients: assessment of patient-reported outcomes in patients randomized to placebo in the COMFORT-I study. Leuk. Res. 2013; 37(8):911-916. [PubMed: 23684482]

11. Cervantes F, Dupriez B, Pereira A, et al. New prognostic scoring system for primary myelofibrosis based on a study of the International Working Group for Myelofibrosis Research and Treatment. Blood. 2009; 113(13):2895-2901. [PubMed: 18988864]

12. Passamonti F, Cervantes F, Vannucchi AM, et al. A dynamic prognostic model to predict survival in primary myelofibrosis: a study by the IWG-MRT (International Working Group for Myeloproliferative Neoplasms Research and Treatment). Blood. 2010; 115(9):1703-1708. [PubMed: 20008785] 
13. Gangat N, Caramazza D, Vaidya R, et al. DIPSS plus: a refined Dynamic International Prognostic Scoring System for primary myelofibrosis that incorporates prognostic information from karyotype, platelet count, and transfusion status. J. Clin. Oncol. 2011; 29(4):392-397. [PubMed: 21149668]

14. Lekovic D, Gotic M, Perunicic-Jovanovic M, et al. Contribution of comorb.i.d.ities and grade of bone marrow fibrosis to the prognosis of survival in patients with primary myelofibrosis. Med. Oncol. 2014; 31(3):869. [PubMed: 24500865]

15. Newberry KJ, Naqvi K, Nguyen KT, et al. Comorb.i.d.ities predict worse prognosis in patients with primary myelofibrosis. Cancer. 2014 doi: 10.1002/cncr.28857.

16. Tefferi A, Vaidya R, Caramazza D, Finke C, Lasho T, Pardanani A. Circulating interleukin (IL)-8, IL-2R, IL-12, and IL-15 levels are independently prognostic in primary myelofibrosis: a comprehensive cytokine profiling study. J. Clin. Oncol. 2011; 29(10):1356-1363. [PubMed: 21300928]

17. Gianelli U, Vener C, Bossi A, et al. The European Consensus on grading of bone marrow fibrosis allows a better prognostication of patients with primary myelofibrosis. Mod. Pathol. 2012; 25(9): 1193-1202. [PubMed: 22627739]

18. Nazha A, Estrov Z, Cortes J, Bueso-Ramos CE, Kantarjian H, Verstovsek S. Prognostic implications and clinical characteristics associated with bone marrow fibrosis in patients with myelofibrosis. Leuk. Lymphoma. 2013; 54(11):2537-2539. [PubMed: 23343175]

19. Guglielmelli P, Lasho TL, Rotunno G, et al. The number of prognostically detrimental mutations and prognosis in primary myelofibrosis: an international study of 797 patients. Leukemia. 2014; 28(9):1804-1810. [PubMed: 24549259]

20. Cazzola M, Kralovics R. From Janus kinase 2 to calreticulin: the clinically relevant genomic landscape of myeloproliferative neoplasms. Blood. 2014; 123(24):3714-3719. [PubMed: 24786775]

21. Rampal R, Al-Shahrour F, Abdel-Wahab O, et al. Integrated genomic analysis illustrates the central role of JAK-STAT pathway activation in myeloproliferative neoplasm pathogenesis. Blood. 2014; 123(22):e123-133. [PubMed: 24740812]

22. Quintas-Cardama A, Kantarjian H, Cortes J, Verstovsek S. Janus kinase inhibitors for the treatment of myeloproliferative neoplasias and beyond. Nat. Rev. Drug Discov. 2011; 10(2):127-140. [PubMed: 21283107]

23. Verstovsek S, Kantarjian H, Mesa RA, et al. Safety and efficacy of INCB018424, a JAK1 and JAK2 inhibitor, in myelofibrosis. N. Engl. J. Med. 2010; 363(12):1117-1127. [PubMed: 20843246]

24. Klampfl T, Gisslinger H, Harutyunyan AS, et al. Somatic mutations of calreticulin in myeloproliferative neoplasms. N. Engl. J Med. 2013; 369(25):2379-2390. [PubMed: 24325356]

25. Nangalia J, Massie CE, Baxter EJ, et al. Somatic CALR mutations in myeloproliferative neoplasms with nonmutated JAK2. N. Engl. J. Med. 2013; 369(25):2391-2405. [PubMed: 24325359]

26. Drachman JG, Millett KM, Kaushansky K. Thrombopoietin signal transduction requires functional JAK2, not TYK2. J. Biol. Chem. 1999; 274(19):13480-13484. [PubMed: 10224114]

27. Tefferi A, Lasho TL, Finke CM, et al. CALR vs JAK2 vs MPL-mutated or triple-negative myelofibrosis: clinical, cytogenetic and molecular comparisons. Leukemia. 2014; 28(7):1472_ 1477. [PubMed: 24402162]

28. Vannucchi AM, Lasho TL, Guglielmelli P, et al. Mutations and prognosis in primary myelofibrosis. Leukemia. 2013; 27(9):1861-1869. [PubMed: 23619563]

29. Lundberg P, Karow A, Nienhold R, et al. Clonal evolution and clinical correlates of somatic mutations in myeloproliferative neoplasms. Blood. 2014; 123(14):2220-2228. [PubMed: 24478400]

30. Tefferi A, Guglielmelli P, Lasho TL, et al. CALR and ASXL1 mutations-based molecular prognostication in primary myelofibrosis: an international study of 570 patients. Leukemia. 2014; 28(7):1494-1500. [PubMed: 24496303]

31. Gupta V, Hari P, Hoffman R. Allogeneic hematopoietic cell transplantation for myelofibrosis in the era of JAK inhibitors. Blood. 2012; 120(7):1367-1379. [PubMed: 22700718] 
32. Incyte Corporation. Jakafi (ruxolitinib) tablets [prescribing information]. 2014. www.incyte.com/ products/uspi_jakafi.pdf

33. Verstovsek S, Mesa RA, Gotlib J, et al. A double-blind, placebo-controlled trial of ruxolitinib for myelofibrosis. N. Engl. J. Med. 2012; 366(9):799-807. [PubMed: 22375971] •• This randomized double-blind placebo-controlled study is one of two pivotal Phase III trials that demonstrated the significant efficacy and favorable tolerability of ruxolitinib in mitigating disease-related splenomegaly and symptoms in patiens with advance myelofibrosis.

34. Harrison C, Kiladjian JJ, Al-Ali HK, et al. JAK inhibition with ruxolitinib versus best available therapy for myelofibrosis. N. Engl. J. Med. 2012; 366(9):787-798. [PubMed: 22375970] •• This pivotal Phase III study demonstrated the superiority of ruxolitinib over conventional therapies in the treatment of patients with advanced myelofibrosis.

35. Pardanani A, Harrison CN, Cortes JE, et al. Results of a randomized, double-blind, placebocontrolled phase III study (JAKARTA) of the JAK2-selective inhibitor fedratinib (SAR302503) in patients with myelofibrosis (MF). Blood. 2013; 122(21):393. Abstract.

36. Sanofi discontinues clinical development of investigational JAK2 agent fedratinib (SAR302503). Paris, France: Nov 18. 2013 press releaseAvailable at: http://men.sanofi.com/Images/ 34935_20131118_JAK-2-FEDRATINIB_en.pdf [accessed August 27, 2014]

37. Zhang Q, Zhang Y, Diamond S, et al. The Janus kinase 2 inhibitor fedratinib inhibits thiamine uptake: a putative mechanism for the onset of Wernicke's encephalopathy. Drug Metab. Dispos. 2014; 42(10):1656-1662. [PubMed: 25063672]

38. Verstovsek S, Tam CS, Wadleigh M, et al. Phase I evaluation of XL019, an oral, potent, and selective JAK2 inhibitor. Leuk. Res. 2014; 38(3):316-322. [PubMed: 24374145]

39. Gowin K, Thapaliya P, Samuelson J, et al. Experience with pegylated interferon alpha-2a in advanced myeloproliferative neoplasms in an international cohort of 118 patients. Haematologica. 2012; 97(10):1570-1573. [PubMed: 22419578]

40. Ianotto JC, Boyer-Perrard F, Gyan E, et al. Efficacy and safety of pegylated-interferon alpha-2a in myelofibrosis: a study by the FIM and GEM French cooperative groups. Br J Haematol. 2013; 162(6):783-791. [PubMed: 23848933]

41. Silver RT, Vandris K, Goldman JJ. Recombinant interferon-alpha may retard progression of early primary myelofibrosis: a preliminary report. Blood. 2011; 117(24):6669-6672. [PubMed: 21518929]

42. Stauffer Larsen T, Iversen KF, Hansen E, et al. Long term molecular responses in a cohort of Danish patients with essential thrombocythemia, polycythemia vera and myelofibrosis treated with recombinant interferon alpha. Leuk Res. 2013; 37(9):1041-1045. [PubMed: 23827351]

43. Shi JG, Chen X, Mcgee RF, et al. The pharmacokinetics, pharmacodynamics, and safety of orally dosed INCB018424 phosphate in healthy volunteers. J. Clin. Pharmacol. 2011; 51(12):1644-1654. [PubMed: 21257798]

44. Chen X, Williams WV, Sandor V, Yeleswaram S. Population pharmacokinetic analysis of orallyadministered ruxolitinib (INCB018424 Phosphate) in patients with primary myelofibrosis (PMF), post-polycythemia vera myelofibrosis (PPV-MF) or post-essential thrombocythemia myelofibrosis (PET MF). J. Clin. Pharmacol. 2013; 53(7):721-730. [PubMed: 23677817]

45. Shi JG, Chen X, Emm T, et al. The effect of CYP3A4 inhibition or induction on the pharmacokinetics and pharmacodynamics of orally administered ruxolitinib (INCB018424 phosphate) in healthy volunteers. J. Clin. Pharmacol. 2012; 52(6):809-818. [PubMed: 21602517]

46. Chen X, Shi JG, Emm T, et al. Pharmacokinetics and pharmacodynamics of orally-administered ruxolitinib (INCB018424 phosphate) in renal and hepatic impairment patients. Clin. Pharmacol. Drug Devel. 2014; 3(1):34-42. [PubMed: 27128228]

47. Quintas-Cardama A, Vaddi K, Liu P, et al. Preclinical characterization of the selective JAK1/2 inhibitor INCB018424: therapeutic implications for the treatment of myeloproliferative neoplasms. Blood. 2010; 115(15):3109-3117. [PubMed: 20130243]

48. Benjamini O, Jain P, Estrov Z, Kantarjian HM, Verstovsek S. Therapeutic effects of ruxolitinib in patients with myelofibrosis without clinically significant splenomegaly. Blood. 2012; 120(13): 2768-2769. [PubMed: 23019204] - Individual cases are presented showing the benefit of 
ruxolitinib for patients without significant splenomegaly, including clinically significant liver size reduction in patients with hepatomegaly after splenectomy.

49. Kvasnicka HM, Thiele J, Bueso-Ramos CE, et al. Effects of five-years of ruxolitinib therapy on bone marrow morphology in patients with myelofibrosis and comparison with best available therapy. Blood. 2013; 122(21):4055. Abstract.

50. Wilkins BS, Radia D, Woodley C, Farhi SE, Keohane C, Harrison CN. Resolution of bone marrow fibrosis in a patient receiving JAK1/JAK2 inhibitor treatment with ruxolitinib. Haematologica. 2013; 98(12):1872-1876. [PubMed: 24056820]

51. Molica M, Serrao A, Saracino R, et al. Disappearance of fibrosis in secondary myelofibrosis after ruxolitinib treatment: new endpoint to achieve? Ann Hematol. 2014 Epub before print, doi: 10.1007/s00277-014-2096-y.

52. Verstovsek S, Mesa RA, Gotlib J, et al. The clinical benefit of ruxolitinib across patient subgroups: analysis of a placebo-controlled, phase III study in patients with myelofibrosis. Br. J. Haematol. 2013; 161(4):508-516. [PubMed: 23480528]

53. Cervantes F, Vannucchi AM, Kiladjian JJ, et al. Three-year efficacy, safety, and survival findings from COMFORT-II, a phase 3 study comparing ruxolitinib with best available therapy for myelofibrosis. Blood. 2013; 122(25):4047-4053. [PubMed: 24174625] • A comprehensive analysis of 3-year data from COMFORT-II, which establishes the efficacy and safety of sustained ruxolitinib therapy and provides compelling evidence of a survival advantage compared with conventional therapy.

54. Verstovsek S, Mesa RA, Gotlib J, et al. The clinical benefit of ruxolitinib across patient subgroups: analysis of a placebo-controlled, Phase III study in patients with myelofibrosis. Br. J. Haematol. 2013; 161(4):508-516. [PubMed: 23480528]

55. Mesa RA, Gotlib J, Gupta V, et al. Effect of ruxolitinib therapy on myelofibrosis-related symptoms and other patient-reported outcomes in COMFORT-I: a randomized, double-blind, placebocontrolled trial. J. Clin. Oncol. 2013; 31(10):1285-1292. [PubMed: 23423753]

56. Harrison CN, Kiladjian J-J, Gisslinger H, et al. Ruxolitinib provides reductions in splenomegaly across subgroups: an analysis of spleen response in the COMFORT-II Study. Blood. 2011; 118:279. Abstract.

57. Harrison CN, Mesa RA, Kiladjian JJ, et al. Health-related quality of life and symptoms in patients with myelofibrosis treated with ruxolitinib versus best available therapy. Br. J. Haematol. 2013; 162(2):229-239. [PubMed: 23672349] - A detailed comparison of the effects of ruxolitinib and traditional therapy on patient-reported outcomes in COMFORT-II.

58. Verstovsek S, Mesa RA, Gotlib J, et al. Efficacy, safety and survival with ruxolitinib in patients with myelofibrosis: results of a median 2-year follow-up of COMFORT-I. Haematologica. 2013; 98(12):1865-1871. [PubMed: 24038026]

59. Guglielmelli P, Biamonte F, Rotunno G, et al. Impact of mutational status on outcomes in myelofibrosis patients treated with ruxolitinib in the COMFORT-II study. Blood. 2014; 123(14): 2157-2160. [PubMed: 24458439]

60. Passamonti F, Caramazza D, Maffioli M. JAK inhibitor in CALR-mutant myelofibrosis. N. Engl. J. Med. 2014; 370(12):1168-1169. [PubMed: 24645956]

61. Mesa RA, Verstovsek S, Gupta V, et al. Improvement in weight and total cholesterol and their association with survival in ruxolitinib-treated patients with myelofibrosis from COMFORT-I. Blood. 2012; 120(21):1733.

62. Cervantes F, Mesa R, Harrison C. JAK inhibitors: beyond spleen and symptoms? Haematologica. 2013; 98(2):160-162. [PubMed: 23372034]

63. Vannucchi AM, Kantarjian H, Kiladjian J-J, et al. A pooled overall survival analysis of the COMFORT Studies: 2 randomized phase 3 trials of ruxolitinib for the treatment of myelofibrosis. Blood. 2013; 122(21):2820.

64. Passamonti F, Maffioli M, Cervantes F, et al. Impact of ruxolitinib on the natural history of primary myelofibrosis: a comparison of the DIPSS and the COMFORT-2 cohorts. Blood. 2014; 123(12): 1833-1835. [PubMed: 24443442] •• Based on a comparison of patients treated in COMFORT-II with historical controls, this survival analysis provides evidence that ruxolitinib influences the 
natural history of primary myelofibrosis by prolonging survival compared with conventional therapy.

65. Talpaz M, Paquette R, Afrin L, et al. Interim analysis of safety and efficacy of ruxolitinib in patients with myelofibrosis and low platelet counts. J. Hematol. Oncol. 2013; 6(1):81. [PubMed: 24283202] - This evaluation of the efficacy and safety of ruxolitinib in patients with low platelet counts supports the use of a low starting dose $(5 \mathrm{mg}$ b.i.d.) with up-titration based on efficacy and tolerability in this patient population.

66. Harrison CN, Gisslinger H, Miller CB, et al. Expand: a phase 1b, open-label, dose-finding study of ruxolitinib in patients with myelofibrosis and baseline platelet counts between $50 \times 109 / \mathrm{L}$ and 99 $\times$ 109/L. Blood. 2012; 120:177. Abstract.

67. Mead A, Milojkovic D, Knaper S, et al. Response to ruxolitinib in patients with intermediate-1, intermediate-2 and high-risk myelofibrosis: results of the UK ROBUST trial. Br. J. Haematol. 2015 In Press.

68. Tabarroki A, Lindner DJ, Visconte V, et al. Ruxolitinib leads to improvement of pulmonary hypertension in patients with myelofibrosis. Leukemia. 2014; 28(7):1486-1493. [PubMed: 24406841] - A study supporting the efficacy of ruxolitinib in mitigating myelofibrosis-related pulmonary hypertension.

69. Verstovsek S, Passamonti F, Rambaldi A, et al. A phase 2 study of ruxolitinib, an oral JAK1 and JAK2 inhibitor, in patients with advanced polycythemia vera who are refractory or intolerant to hydroxyurea. Cancer. 2013; 120(4):513-520. [PubMed: 24258498]

70. Vannuchi AM, Kiladjian JJ, Griesshammer M, et al. Ruxolitinib versus standard therapy for the treatment of polycythemia vera. N. Engl. J. Med. 2015; 372(5):426-435. [PubMed: 25629741]

71. Barosi G, Agarwal M, Zweegman S, et al. An individual patient supply program for ruxolitinib for the treatment of patients with primary myelofibrosis (PMF), post-polycythemia vera myelofibrosis (PPV-MF), or post-essential thrombocythemia myelofibrosis (PET-MF). Blood. 2012; 120:2844. Abstract.

72. Andreoli A, Rey J, Dauriac C, et al. Ruxolitinib therapy in myelofibrosis: analysis of 241 patients treated in compassionate use (French "ATU" program) by the French Intergroup of Myeloproliferative Neoplasms (FIM). Blood. 2012; 120:2841. Abstract.

73. Vargas P, Ovilla R, Alvarado M, et al. Compassionate Use Program (CUP) with ruxolitinib in Mexican patients with primary myelofibrosis (PMF), post-polycythemia vera myelofibrosis (PPV MF), and post-essential thrombocythemia myelofibrosis (PET - MF). Blood. 2012; 120:5067. Abstract.

74. Nguyen H, Pham A, Perkins C, Linder A, Fechter L, Gotlib J. FDA-approved ruxolitinib in patients with myelofibrosis: the Stanford Experience. Blood. 2012; 120:1747. Abstract.

75. Geyer H, Cannon K, Knight E, et al. Ruxolitinib in clinical practice for therapy of myelofibrosis: Single USA center experience following Food and Drug Administration approval. Leuk. Lymphoma. 2014; 55(1):195-197. [PubMed: 23647081]

76. Andreoli A, Verger E, Robin M, et al. Clinical resistance to ruxolitinib is more frequent in patients without MPN-associated mutations and is rarely due to mutations in the JAK2 kinase drug-binding domain. Blood. 2013; 122:1591. Abstract.

77. Deshpande A, Reddy MM, Schade GO, et al. Kinase domain mutations confer resistance to novel inhibitors targeting JAK2V617F in myeloproliferative neoplasms. Leukemia. 2012; 26(4):708715. [PubMed: 21926964]

78. Koppikar P, Bhagwat N, Kilpivaara O, et al. Heterodimeric JAK-STAT activation as a mechanism of persistence to JAK2 inhibitor therapy. Nature. 2012; 489(7414):155-159. [PubMed: 22820254]

79. Gisslinger H, Schalling M, Gisslinger B, Skrabs C, Mullauer L, Kralovics R. Restoration of response to ruxolitinib upon brief withdrawal in two patients with myelofibrosis. Am. J. Hematol. 2014; 89(3):344-346. [PubMed: 24273107]

80. Verstovsek S, Gotlib J, Gupta V, et al. Management of cytopenias in patients with myelofibrosis treated with ruxolitinib and effect of dose modifications on efficacy outcomes. OncoTargets Ther. 2013; 7:13-21.

81. Heine A, Held SA, Daecke SN, et al. The JAK-inhibitor ruxolitinib impairs dendritic cell function in vitro and in vivo. Blood. 2013; 122(7):1192-1202. [PubMed: 23770777] 
82. Barosi G, Campanelli R, Fois G, et al. Decrease of T regulatory cells in patients with myelofibrosis receiving ruxolitinib. Blood. 2013; 122:4057. Abstract.

83. Massa M, Rosti V, Campanelli R, Fois G, Barosi G. Rapid and long-lasting decrease of Tregulatory cells in patients with myelofibrosis treated with ruxolitinib. Leukemia. 2014; 28(2): 449-451. [PubMed: 24145312]

84. Wathes R, Moule S, Milojkovic D. Progressive multifocal leukoencephalopathy associated with ruxolitinib. N. Engl. J. Med. 2013; 369(2):197-198. [PubMed: 23841743]

85. Caocci G, Murgia F, Podda L, Solinas A, Atzeni S, La Nasa G. Reactivation of hepatitis B virus infection following ruxolitinib treatment in a patient with myelofibrosis. Leukemia. 2014; 28(1): 225-227. [PubMed: 23929216]

86. Wysham NG, Sullivan DR, Allada G. An opportunistic infection associated with ruxolitinib, a novel janus kinase 1,2 inhibitor. Chest. 2013; 143(5):1478-1479. [PubMed: 23648912]

87. Hopman RK, Lawrence SJ, Oh ST. Disseminated tuberculosis associated with ruxolitinib. Leukemia. 2014; 28(8):1750-1751. [PubMed: 24625550]

88. Tong LX, Jackson J, Kerstetter J, Worswick SD. Reactivation of herpes simplex virus infection in a patient undergoing ruxolitinib treatment. J. Am. Acad. Dermatol. 2014; 70(3):e59-60. [PubMed: 24528917]

89. Lee SC, Feenstra J, Georghiou PR. Pneumocystis jiroveci pneumonitis complicating ruxolitinib therapy. BMJ Case Rep. 2014; 2014 doi: 10.1136/bcr-2014-204950.

90. Tefferi A, Pardanani A. Serious adverse events during ruxolitinib treatment discontinuation in patients with myelofibrosis. Mayo Clin. Proc. 2011; 86(12):1188-1191. [PubMed: 22034658]

91. Novartis Pharmaceuticals Canada Inc. ${ }^{P r}$ JAKAVI (ruxolitinib tablets) [Product Monograph]. www.novartis.ca

92. Novartis Pharma Ag. JAKAVI Product Website. www.jakavi.com/index.jsp

93. European Medicines Agency. Jakavi (ruxolitinib) [product information]. www.ema.europa.eu 


\section{EXECUTIVE SUMMARY}

- $\quad$ Ruxolitinib is a potent JAK1 and JAK2 inhibitor.

- $\quad$ Ruxolitinib reduced splenomegaly and circulating levels of inflammatory cytokines, preferentially eliminated neoplastic cells and prolonged survival in a myeloproliferative neoplasm mouse model.

- Ruxolitinib is currently the only pharmacotherapy approved in myelofibrosis (MF).

\section{Clinical efficacy}

- $\quad$ Ruxolitinib provided significant improvement of splenomegaly, MF-related symptoms and quality-of-life measures in pivotal Phase III studies compared with placebo or best available therapy.

- $\quad$ Efficacy was generally sustained with continued therapy.

- $\quad$ Overall evidence from the Phase III studies as well as cross-study comparisons with historical controls suggests that ruxolitinib is associated with a survival advantage compared with placebo and conventional therapy.

- $\quad$ Ruxolitinib may halt or reverse bone marrow fibrosis in some patients with MF.

\section{Safety \& tolerability}

- Thrombocytopenia and anemia are common dose-dependent adverse events that can generally be managed by dose adjustments and red blood cell transfusions (for anemia).

- The monitoring of platelet counts as well as the use of platelet countdependent starting doses and dose reductions are essential to ensure continued therapy with maximum treatment benefit.

- $\quad$ Reduced starting doses are recommended for patients with hepatic or moderate or severe renal impairment.

- Because ruxolitinib may have immunosuppressive properties, precautions should be taken to assess the risk of developing serious infections, to resolve serious infections before starting therapy and to withhold therapy for patients who have progressive multifocal leukoencephalopathy.

\section{Regulatory affairs}

- Ruxolitinib is approved in the USA for the treatment of patients with intermediate-risk or high-risk MF and of patients with PV who have had an inadequate response to or are intolerant of hydoxyurea..

- $\quad$ Outside the United States, ruxolitinib is approved for the treatment of MFrelated splenomegaly and symptoms in 82 countries worldwide. 


\section{Table 1}

Efficacy of ruxolitinib in the COMFORT trials

\begin{tabular}{|c|c|c|c|c|}
\hline \multirow[b]{2}{*}{ Efficacy Parameter } & \multicolumn{2}{|c|}{ COMFORT-I [33,52] } & \multicolumn{2}{|c|}{ COMFORT-II $[34,53]$} \\
\hline & $\operatorname{RUX}(\mathbf{n}=155)$ & $\operatorname{PBO}(n=154)$ & $\underset{146)}{\operatorname{RUX}(n=}$ & BAT $(n=73)$ \\
\hline Primary analysis & \multicolumn{2}{|c|}{24 Weeks } & \multicolumn{2}{|c|}{48 Weeks } \\
\hline \multicolumn{5}{|l|}{ Spleen volume } \\
\hline Patients with $\geq 35 \%$ reduction from BL, $\%$ & 41.9 & 0.7 & 28.0 & 0 \\
\hline Mean change from $\mathrm{BL}, \%$ & -31.6 & 8.1 & -30.1 & 7.3 \\
\hline \multicolumn{5}{|l|}{ Symptoms and QoL } \\
\hline Patients with $250 \%$ TSS reduction from BL, $\%$ & 45.9 & 5.3 & & \\
\hline \multicolumn{5}{|l|}{ Mean change from BL, $\%$} \\
\hline TSS & -46.1 & 41.8 & & \\
\hline PROMIS Fatigue Scale & -15.6 & 9.1 & & \\
\hline \multicolumn{5}{|l|}{ Mean change from BL, symptom score } \\
\hline EORTC QLQ-C30 Fatigue subscale & & & -12.8 & 0.4 \\
\hline EORTC QLQ-C30 Global Health Status/QoL & 12.3 & -3.4 & 9.1 & 3.4 \\
\hline Long-term follow-up (median) & \multicolumn{2}{|c|}{149 Weeks } & \multicolumn{2}{|c|}{151 Weeks } \\
\hline Patients remaining on therapy, $\%$ & \multicolumn{2}{|l|}{49.7} & \multicolumn{2}{|l|}{45.2} \\
\hline \multicolumn{5}{|l|}{ Spleen volume } \\
\hline $\begin{array}{l}\text { Proportion of patients with } \geq 35 \% \text { reduction at any time during follow- } \\
\text { up, } \%\end{array}$ & \multicolumn{2}{|l|}{59} & \multicolumn{2}{|l|}{51} \\
\hline Probability of maintaining response during follow-up & \multicolumn{2}{|l|}{0.53} & \multicolumn{2}{|l|}{0.50} \\
\hline
\end{tabular}

BAT: Best available therapy; BL: Baseline; EORTC QLQ-C30: European Organisation for Research and Treatment of Cancer Quality of Life 30 Questionnaire; PBO: Placebo; PROMIS: Patient-Reported Outcomes Measurement System; QoL: Quality of life; RUX: Ruxolitinib; TSS: Total symptom score. 


\section{Table 2}

Overall survival in the COMFORT trials.

\begin{tabular}{|c|c|c|}
\hline Median Follow-up & HR $(95 \%$ CI $)$ & p Value* \\
\hline COMFORT-I & \multicolumn{2}{|c|}{$R U X(n=155)$ vs $P B O(n=154)$} \\
\hline 1 year (51 weeks) [33] & $0.50(0.25-0.98)$ & 0.04 \\
\hline 2 years (102 weeks) $[58]$ & $0.58(0.36-0.95)$ & 0.03 \\
\hline 3 years (149 weeks) [52] & $0.69(0.46-1.03)$ & 0.067 \\
\hline COMFORT-II & \multicolumn{2}{|c|}{$R U X(n=146)$ vs $B A T(n=73)$} \\
\hline 1 year (52 weeks) [34] & \multicolumn{2}{|l|}{$0.70(0.20-2.49)$} \\
\hline 2 years (112 weeks) [62] & $0.51(0.27-0.99)$ & 0.041 \\
\hline 3 years (151 weeks) [53] & $0.48(0.28-0.85)$ & 0.009 \\
\hline COMFORT-I + COMFORT-II & \multicolumn{2}{|c|}{$R U X(n=301)$ vs $P B O$ or $B A T(n=227)$} \\
\hline 3 years $[63]$ & $0.65(0.46-0.90)$ & 0.01 \\
\hline
\end{tabular}

Future Oncol. Author manuscript; available in PMC 2016 June 24. 
Table 3

Hematologic laboratory test abnormalities in the COMFORT trials during randomized treatment

\begin{tabular}{lcccc}
\hline & \multicolumn{2}{c}{ COMFORT-I [33] } & COMFORT-II [34] \\
\hline Event, Percentage of patients & Ruxolitinib $(\mathbf{n}=\mathbf{1 5 5})$ & Placebo $(\mathbf{n}=\mathbf{1 5 1})$ & Ruxolitinib (n= 146) & BAT (n = 73) \\
\hline Anemia & & & & \\
All grades & 96.1 & 86.8 & 96 & 94 \\
Grade $\geq 3$ & 45.2 & 19.2 & 42 & 31 \\
Thrombocytopenia & & & & \\
All grades & 69.7 & 30.5 & 68 & 7 \\
Grade $\geq 3$ & 12.9 & 1.3 & 8 & \\
Neutropenia & & & & NR \\
All grades & 18.7 & 4.0 & NR & NR \\
Grade $\geq 3$ & 7.1 & 2.0 & NR \\
\hline
\end{tabular}

BAT: Best available therapy; NR: Not reported. 


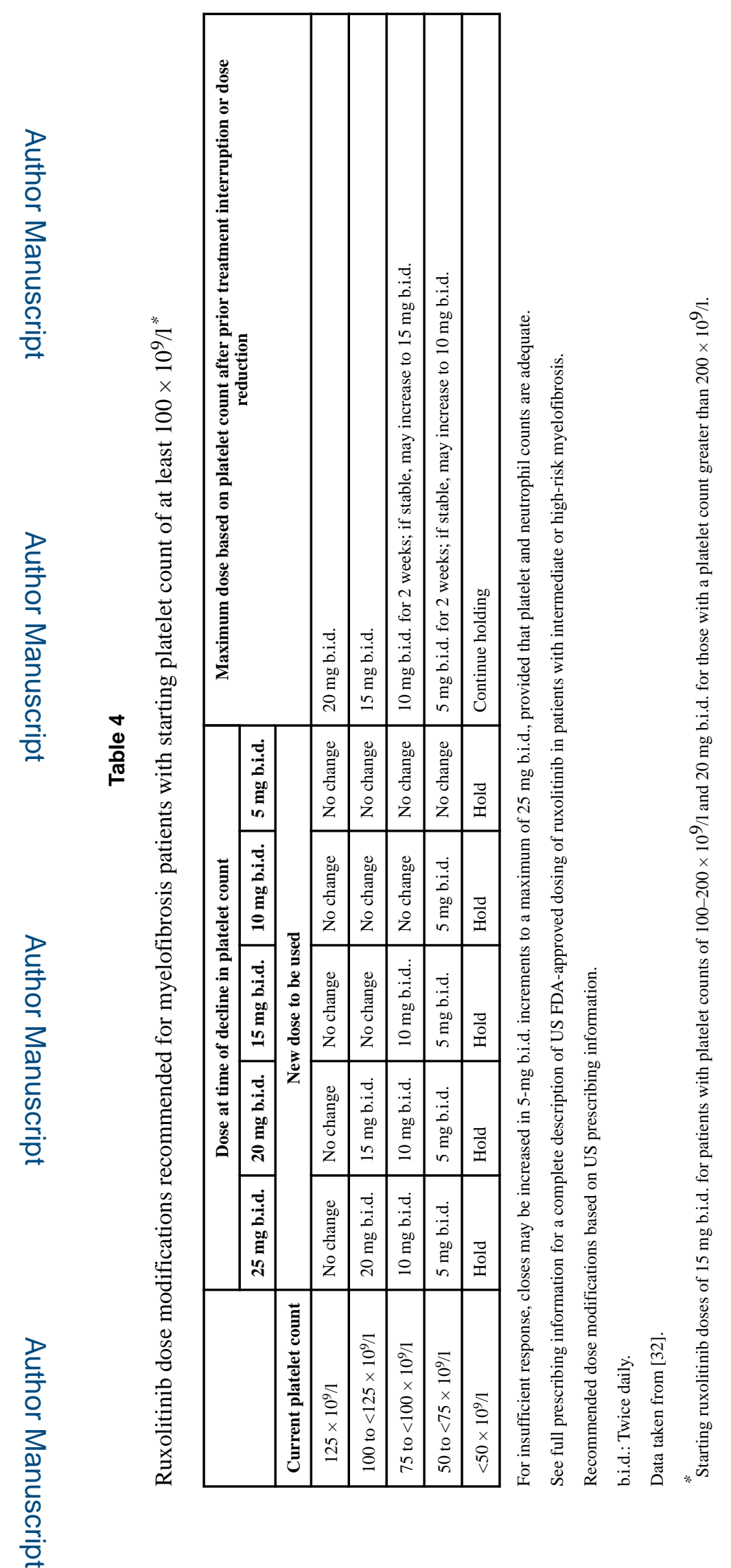

Future Oncol. Author manuscript; available in PMC 2016 June 24. 


\section{Table 5}

Ruxolitinib dose modifications recommended for myelofibrosis patients with a starting platelet count of at least $50 \times 10^{9} / 1$ but less than $100 \times 10^{9} / 1^{*}$

\begin{tabular}{|l|c|}
\hline Current platelet count & Dosing recommendation \\
\hline$<25 \times 10^{9} / 1$ & Interrupt treatment \\
\hline 25 to $<35 \times 10^{9} / 1$ and $<20 \%$ decrease during the prior 4 weeks & $\begin{array}{c}\text { Decrease dose by } 5 \mathrm{mg} \text { q.d. or maintain the current dose if it is } 5 \mathrm{mg} \\
\text { q.d. }\end{array}$ \\
\hline 25 to $<35 \times 10^{9} / 1$ and $\geq 20 \%$ decrease during prior 4 weeks & $\begin{array}{c}\text { Decrease dose by } 5 \mathrm{mg} \text { b.i.d. or use } 5 \mathrm{mg} \text { q.d. if the current dose is } 5 \\
\mathrm{mg} \text { b.i.d. or q.d. }\end{array}$ \\
\hline $\begin{array}{l}\geq 40 \times 10^{9} / 1 \text { and } \Omega 0 \% \text { decrease during prior } 4 \text { weeks, ANC }>1 \times \\
10^{9} / \mathrm{l} \text { and no dose reductions or treatment interruptions for AE or } \\
\text { hematologic toxicity during the prior } 4 \text { weeks }\end{array}$ & $\begin{array}{c}\text { Increase dose by increments of } 5 \mathrm{mg} \text { q.d. to a maximum of } 10 \mathrm{mg} \\
\text { bi.d. if response is insufficient }\end{array}$ \\
\hline
\end{tabular}

See full prescribing information for a complete description of US FDA-approved dosing of ruxolitinib in patients with intermediate or high-risk myelofibrosis.

AE: Adverse event; ANC: Absolute neutrophil count; b.i.d.: Twice daily; q.d.: Once daily.

Data taken from [32].

Starting ruxolitinib dose of $5 \mathrm{mg}$ b.i.d. Recommended dose modifications based on US prescribing information. 
Table 6

Common adverse events ${ }^{*}$ in patients receiving ruxolitinib in COMFORT-I during randomized treatment.

\begin{tabular}{|c|c|c|c|c|c|c|}
\hline \multirow[t]{2}{*}{ Adverse events ${ }^{*}$, percentage of patients } & \multicolumn{3}{|c|}{ Ruxolitinib (n = 155) } & \multicolumn{3}{|c|}{ Placebo $(\mathbf{n}=151)$} \\
\hline & All grades & Grade 3 & Grade 4 & All grades & Grade 3 & Grade 4 \\
\hline Bruising $^{\dagger}$ & 23.2 & 0.6 & 0 & 14.6 & 0 & 0 \\
\hline Dizziness ${ }^{t}$ & 18.1 & 0.6 & 0 & 7.3 & 0 & 0 \\
\hline Headache & 14.8 & 0 & 0 & 5.3 & 0 & 0 \\
\hline Urinary tract infection ${ }^{\xi}$ & 9.0 & 0 & 0 & 5.3 & 0.7 & 0.7 \\
\hline Weight gain// & 7.1 & 0.6 & 0 & 1.3 & 0.7 & 0 \\
\hline Flatulence & 5.2 & 0 & 0 & 0.7 & 0 & 0 \\
\hline Herpes zoster ${ }^{q}$ & 1.9 & 0 & 0 & 0.7 & 0 & 0 \\
\hline
\end{tabular}

Data taken from [32].

National Cancer Institute Common Terminology Criteria for Adverse Events, version 3.0; cytopenias were excluded.

Includes contusion, ecchymosis, hematoma, injection-site hematoma, periorbital hematoma, vessel puncture-site hematoma, increased tendency to bruise, petechiae, purpura.

${ }^{*}$ Includes dizziness, postural dizziness, vertigo, balance disorder, Meniere's disease, labyrinthitis.

$\xi_{\text {Includes urinary tract infection, cystitis, urosepsis, urinary tract infection bacterial, kidney infection, pyuria, bacteria urine, bacteria urine }}$ identified, nitrite urine present

"Includes weight increased, abnormal weight gain.

II Includes herpes zoster and postherpetic neuralgia. 